\title{
Rare respiratory diseases are ready for primetime: from Rare Disease Day to the European Reference Networks
}

\author{
Marc Humbert (1) $1,2,3$ and Thomas 0. Wagner ${ }^{4}$
}

\begin{abstract}
Affiliations: ${ }^{1}$ Faculté de Médecine, Université Paris-Sud, Université Paris-Saclay, Le Kremlin Bicêtre, France. ${ }^{2}$ Service de Pneumologie, Centre de Référence de l'Hypertension Pulmonaire, Hôpital Bicêtre (Assistance Publique Hôpitaux de Paris), Le Kremlin-Bicêtre, France. ${ }^{3}$ Inserm UMR-S 999, Hôpital Marie Lannelongue, Le Plessis Robinson, France. ${ }^{4}$ Frankfurt Reference Center for Rare Diseases (FRZSE), Dept. of Pneumology and Allergology, Universitätsklinikum Frankfurt am Main, Frankfurt am Main, Germany.
\end{abstract}

Correspondence: Marc Humbert, Service de Pneumologie, Centre de Référence de l'Hypertension Pulmonaire, Hôpital Bicêtre (Assistance Publique Hôpitaux de Paris), 78 rue du Général Leclerc, Le KremlinBicêtre, 94270, France. E-mail: marc.humbert@aphp.fr

@ERSpublications

The ERN-LUNG network is currently made up of 60 centres in 12 countries and is focused on rare respiratory diseases http://ow.ly/CG0d3089xDC

Cite this article as: Humbert M, Wagner TO. Rare respiratory diseases are ready for primetime: from Rare Disease Day to the European Reference Networks. Eur Respir J 2017; 49: 1700085 [https://doi.org/10.1183/ 13993003.00085-2017].

Rare diseases are life-threatening or chronically debilitating conditions which are of such low prevalence (fewer than 1 in 2000 people) that special combined efforts are needed to address them [1]. Launched in 2008 by Rare Diseases Europe (EURORDIS), a non-governmental patient-driven alliance representing 733 rare disease patient organisations in 64 countries, Rare Disease Day (figure 1) takes place on the last day of February each year. The main objective of Rare Disease Day is to raise awareness amongst the general public and decision-makers about rare diseases and their impact on patients' lives [2]. In 2017, Rare Disease Day will emphasise that research brings hope to people living with a rare disease [2]. Indeed, due to the rarity and diversity of rare diseases, research needs to be international to ensure that experts, researchers and clinicians are connected, that clinical trials are multinational, and that patients can benefit from the pooling of resources across borders [2].

Supporting education, research and care related to rare diseases is very timely in Europe, with the announcement on December 152016 that the European Commission's Board of Member States had approved 23 European Reference Networks (ERNs), including one for rare respiratory diseases (ERN-LUNG; table 1) [3]. Furthermore, in order to share knowledge and expertise more efficiently, the European Union Committee of Experts on Rare Diseases (EUCERD) has adopted recommendations on quality criteria for centres of expertise in rare diseases in member states [4]. Centres of expertise should allow the concentration of both expertise and patient numbers in one place to tackle rare or complex diseases and conditions more effectively [3,4]. Developing centres of expertise and ERNs in the field of rare diseases was proposed in the European Council recommendation for action in the field of rare diseases and more recently in the cross-border healthcare directive as a means of organising care for the thousands of heterogeneous rare conditions affecting scattered patient populations across Europe [4].

The ERN-LUNG is a network of European healthcare providers dedicated to ensuring and promoting excellence in care and research for the benefit of patients affected by rare respiratory diseases.

Received: Jan 132017 | Accepted: Jan 162017

Conflict of interest: Disclosures can be found alongside this article at erj.ersjournals.com

Copyright @ERS 2017 
FIGURE 1 The logo of Rare Disease Day (www.rarediseaseday.org).

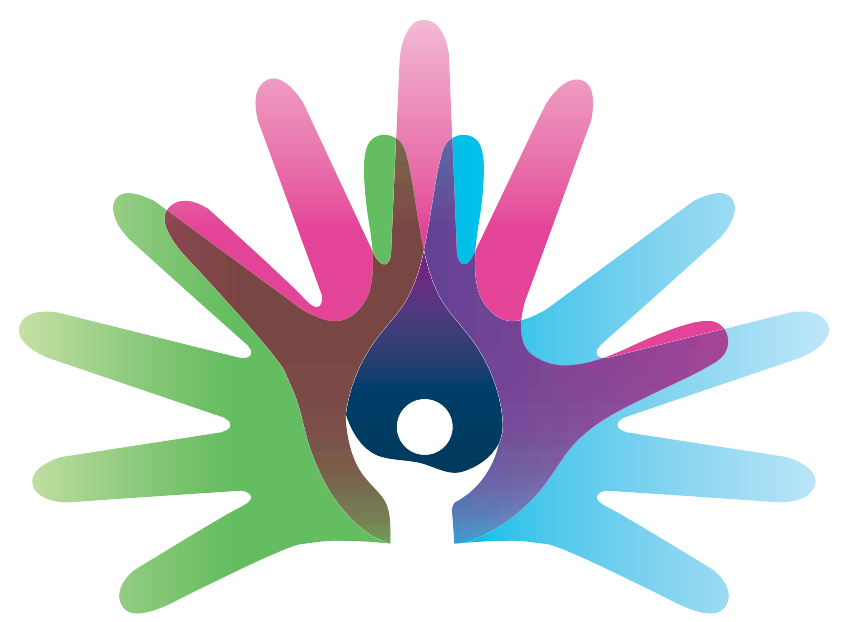

ERN-LUNG's vision is to be a European knowledge hub for such diseases and to decrease morbidity and mortality from them in people of all ages. It is a non-profit, international, professional, patient-centric and scientific network and it is committed Europe-wide and globally to the prevention, diagnosis and treatment of rare respiratory diseases through patient care and advocacy, education and research. In keeping with these goals, ERN-LUNG will interact with both national and international organisations which have similar goals.

ERN-LUNG is currently made up of 60 centres in 12 countries and is organised into nine core networks representing the diversity of diseases and conditions affecting the respiratory system (figure 2, table 2). The current core networks are interstitial lung diseases [5-21], cystic fibrosis [22-25], pulmonary hypertension

TABLE 1 Outcome of the 2016 call [3] to establish European Reference Networks (ERNs), as approved by the European Commission's Board of Member States on December 152016

\begin{tabular}{l} 
Network \\
\hline ERN BOND \\
ERN CRANIO \\
Endo-ERN \\
ERN EpiCARE \\
ERKNet \\
ERN RND \\
ERNICA \\
ERN-LUNG \\
ERN Skin \\
ERN EURACAN \\
ERN EuroBloodNet \\
ERN EURO-NMD \\
ERN EYE \\
ERN GENTURIS \\
ERN GUARD-HEART \\
ERN ITHACA \\
MetabERN \\
ERN PaedCan \\
ERN RARE-LIVER \\
ERN ReCONNET \\
ERN RITA \\
ERN TRANSPLANT-CHILD \\
VASCERN
\end{tabular}

Focus

ENT: ear, nose and throat. 

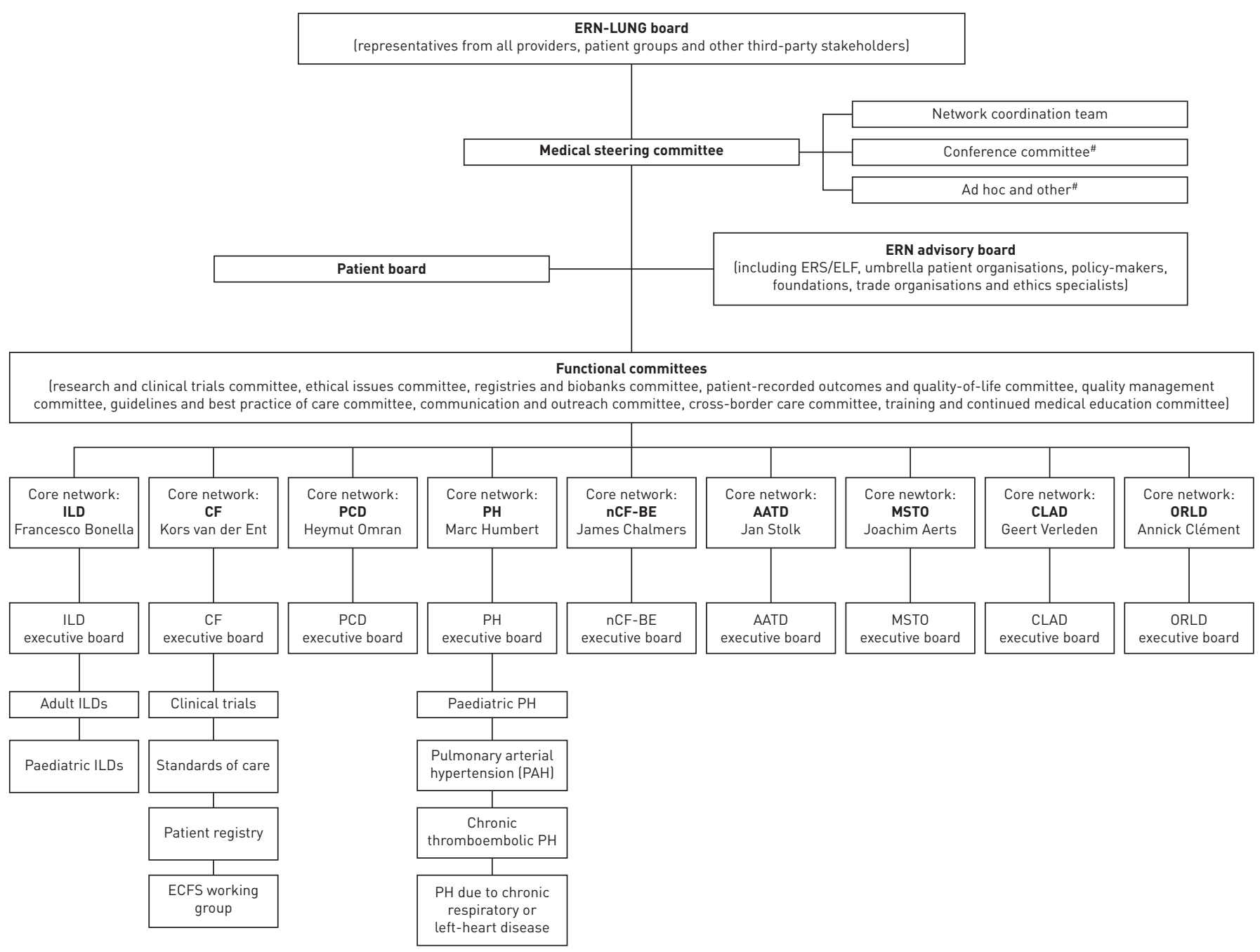

FIGURE 2 The structure of the European Reference Network on rare respiratory diseases (ERN-LUNG). ERS: European Respiratory Society; ELF: European Lung Foundation; ILD: interstitial lung disease; CF: cystic fibrosis; PCD: primary ciliary dyskinesis; PH: pulmonary hypertension; PAH: pulmonary arterial hypertension; nCF-BE: nonCF-bronchiectasis; AATD: $\alpha_{1}$-antitrypsin deficiency; MSTO: mesothelioma; CLAD: chronic lung allograft dysfunction; ORLD: other rare lung diseases. " : if installed by the Medical Steering Committee

[26-31], primary ciliary dyskinesia [32-37], non-cystic fibrosis bronchiectasis [38-40], $\alpha_{1}$-antitrypsin deficiency [41], mesothelioma [42], chronic lung allograft dysfunction [43-45] and "other rare lung diseases" (e.g. pulmonary malformations, congenital central hypoventilation syndrome etc) [46-49]. In addition to these thematic subgroups, ERN-LUNG is also organised into functional committees whose aims are to tackle overarching topics affecting all of the current and future core networks, including research and clinical trials, ethical issues, registries and biobanks, patient-reported outcomes and quality-of-life, quality management, guidelines and best practice of care, communication and outreach, cross-border care, and training and continued medical education.

The ERN-LUNG's current set-up will evolve with the inclusion of more members and partners after it is formally established. The creation of a ninth core network on "other rare lung diseases" is intended to serve as an intermediate solution to the question of the formal creation of additional core networks over the next 5 years, covering groups that could not formally become core networks in the initial application stage. The strategic plan for ERN-LUNG is set out in a multi-annual work plan submitted in response to the call for Framework Partnership Agreements for the period 2017-2021 (Chafea: HP-ERN-2016). The plan sets out an evaluation strategy that will be followed to review the ERN-LUNG's achievements within the first 5 years of its establishment.

The ERN awarding ceremony will take place on March 9-10, in Vilnius, Lithuania, in the presence of ERN coordinators and patients' representatives. A few weeks later, the ERN-LUNG kick-off meeting will take place on April 4-5 in Frankfurt with all the healthcare providers and patients' representatives attending. 
TABLE 2 Disposition of the medical steering committee of the European Reference Network on rare respiratory diseases (ERN-LUNG)

Committee position

Candidate

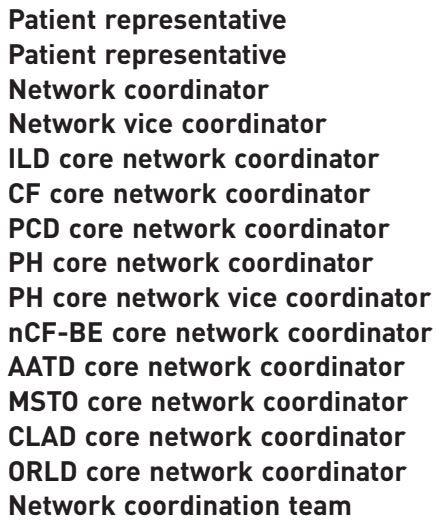

H. de Keyser, Brussels, Belgium

G. Meszaros, Budapest, Hungary

T.O.F. Wagner, Frankfurt, Germany

M. Humbert, Paris, France

F. Bonella, Essen, Germany

K. van der Ent, Utrecht, The Netherlands

H. Omran, Münster, Germany

M. Humbert, Paris, France

N. Galiè, Bologna, Italy

J, Chalmers, Dundee, UK

J. Stolk, Leiden, The Netherlands

J. Aerts, Rotterdam, The Netherlands

G. Verleden, Leuven, Belgium

A. Clément, Paris, France

A. Pfalz, Frankfurt, Germany

ILD: interstitial lung disease; CF: cystic fibrosis; PCD: primary ciliary dyskinesis; PH: pulmonary hypertension; nonCF-BE: nonCF-bronchiectasis; AATD: $\alpha_{1}$-antitrypsin deficiency; MSTO: mesothelioma; CLAD: chronic lung allograft dysfunction; ORLD: other rare lung diseases.

The European Respiratory Society has always been very supportive of rare pulmonary disease research, education and care, and the society's publications regularly disseminate novel data and guidelines in these fields [50, 51]. Of note, the society will endorse the 7th International Meeting on Pulmonary Rare Diseases and Orphan Drugs, which will take place in Milan, Italy on February 24-25. This conference, chaired by Dr Sergio Harari, Chief Editor of the European Respiratory Review, is dedicated entirely to rare pulmonary diseases and rare variants of more common pulmonary conditions. The proceedings from this conference will be published in the European Respiratory Review and updates from the ERN-LUNG will feature regularly in the European Respiratory Journal. Rare respiratory diseases are indeed ready for primetime!

\section{References}

$1 \quad$ Harari S, Lau EMT, Tamura Y, et al. Rare (Pulmonary) Disease Day: "Feeding the breath, Energy for life!" Eur Respir J 2015; 45: 297-300.

2 Rare Diseases Europe (EURORDIS). What is rare disease day? www.rarediseaseday.org/article/ what-is-rare-disease-day Date last accessed: December 262016.

3 The European Commission Directorate of Health and Food Safety. European reference networks: call for applications 2016. http://ec.europa.eu/health/ern/implementation/call_en Date last accessed: December 262016.

4 Kamel N. European reference networks: moving towards a tangible outcome of the European Union's cross-border healthcare directive. Eur Respir J 2016; 48: 1564-1568.

5 Bonella F, Wijsenbeek M, Molina-Molina M, et al. European IPF patient charter: unmet needs and a call to action for healthcare policymakers. Eur Respir J 2016; 47: 597-606.

6 Fischer A, Antoniou KM, Brown KK, et al. An official European Respiratory Society/American Thoracic Society research statement: interstitial pneumonia with autoimmune features. Eur Respir J 2015; 46: 976-987.

7 Behr J, Kreuter M, Hoeper MM, et al. Management of patients with idiopathic pulmonary fibrosis in clinical practice: the INSIGHTS-IPF registry. Eur Respir J 2015; 46: 186-196.

8 Ryerson CJ, Cottin V, Brown KK, et al. Acute exacerbation of idiopathic pulmonary fibrosis: shifting the paradigm. Eur Respir J 2015; 46: 512-520.

9 Collard HR, Bradford WZ, Cottin V, et al. A new era in idiopathic pulmonary fibrosis: considerations for future clinical trials. Eur Respir J 2015; 46: 243-249.

10 Harari S, Torre O, Cassandro R, Moss J. The changing face of a rare disease: lymphangioleiomyomatosis. Eur Respir J 2015; 46: 1471-1485.

11 Taveira-DaSilva AM, Jones AM, Julien-Williams P, et al. Severity and outcome of cystic lung disease in women with tuberous sclerosis complex. Eur Respir J 2015; 45: 171-180.

12 Mourah S, How-Kit A, Meignin V, et al. Recurrent NRAS mutations in pulmonary Langerhans cell histiocytosis. Eur Respir J 2016; 47: 1785-1796.

13 Borie R, Tabèze L, Thabut G, et al. Prevalence and characteristics of TERT and TERC mutations in suspected genetic pulmonary fibrosis. Eur Respir J 2016; 48: 1721-1731.

14 Newton CA, Batra K, Torrealba J, et al. Telomere-related lung fibrosis is diagnostically heterogeneous but uniformly progressive. Eur Respir J 2016; 48: 1710-1720.

15 Clement A, de Blic J, Epaud R, et al. Management of children with interstitial lung diseases: the difficult issue of acute exacerbations. Eur Respir J 2016; 48: 1559-1563. 
16 Cramer C, Schlünssen V, Bendstrup E, et al. Risk of hypersensitivity pneumonitis and interstitial lung diseases among pigeon breeders. Eur Respir J 2016; 48: 818-825.

17 Nunes H, Schubel K, Piver D, et al. Nonspecific interstitial pneumonia: survival is influenced by the underlying cause. Eur Respir J 2015; 45: 746-755.

18 Cozier YC. Assessing the worldwide epidemiology of sarcoidosis: challenges and future directions. Eur Respir J 2016; 48: 1545-1548.

19 Jamilloux Y, Maucort-Boulch D, Kerever S, et al. Sarcoidosis-related mortality in France: a multiple-cause-of-death analysis. Eur Respir J 2016; 48: 1700-1709.

20 Arkema EV, Grunewald J, Kullberg S, et al. Sarcoidosis incidence and prevalence: a nationwide register-based assessment in Sweden. Eur Respir J 2016; 48: 1690-1699.

21 Li L, Silveira LJ, Hamzeh N, et al. Beryllium-induced lung disease exhibits expression profiles similar to sarcoidosis. Eur Respir J 2016; 47: 1797-1808.

22 Elborn JS, Bell SC, Madge SL, et al. Report of the European Respiratory Society/European Cystic Fibrosis Society task force on the care of adults with cystic fibrosis. Eur Respir J 2016; 47: 420-428.

23 Burgel PR, Bellis G, Olesen HV, et al. Future trends in cystic fibrosis demography in 34 European countries. Eur Respir J 2015; 46: 133-141.

24 Stephenson AL, Tom M, Berthiaume Y, et al. A contemporary survival analysis of individuals with cystic fibrosis: a cohort study. Eur Respir J 2015; 45: 670-679.

25 Braido F, Baiardini I, Sumberesi M, et al. Public awareness on cystic fibrosis: results from a national pragmatic survey. Eur Respir J 2015; 46: 264-267.

26 Galiè N, Humbert M, Vachiery JL, et al. 2015 ESC/ERS guidelines for the diagnosis and treatment of pulmonary hypertension. Eur Respir J 2015; 46: 903-975.

27 Montani D, Lau EM, Dorfmüller P, et al. Pulmonary veno-occlusive disease. Eur Respir J 2016; 47: 1518-1534.

28 Girerd B, Montani D, Jaïs X, et al. Genetic counselling in a national referral centre for pulmonary hypertension. Eur Respir J 2016; 47: 541-552.

29 Savale L, Chaumais MC, Sitbon O, et al. Pulmonary arterial hypertension in patients treated with interferon. Eur Respir J 2015; 46: 1851-1853.

30 Levy M, Eyries M, Szezepanski I, et al. Genetic analyses in a cohort of children with pulmonary hypertension. Eur Respir J 2016; 48: 1118-1126.

31 Ghigna MR, Guignabert C, Montani D, et al. BMPR2 mutation status influences bronchial vascular changes in pulmonary arterial hypertension. Eur Respir J 2016; 48: 1668-1681.

32 Lucas JS, Barbato A, Collins SA, et al. European Respiratory Society guidelines for the diagnosis of primary ciliary dyskinesia. Eur Respir J 2017; 49: 1601090.

33 Behan L, Dunn Galvin A, Rubbo B, et al. Diagnosing primary ciliary dyskinesia: an international patient perspective. Eur Respir J 2016; 48: 1096-1107.

34 Goutaki M, Meier AB, Halbeisen FS, et al. Clinical manifestations in primary ciliary dyskinesia: systematic review and meta-analysis. Eur Respir J 2016; 48: 1081-1095.

35 Werner C, Lablans M, Ataian M, et al. An international registry for primary ciliary dyskinesia. Eur Respir J 2016; 47: 849-859.

36 Jackson CL, Behan L, Collins SA, et al. Accuracy of diagnostic testing in primary ciliary dyskinesia. Eur Respir J 2016; 47: 837-848.

37 Lucas JS, Behan L, Dunn Galvin A, et al. A quality-of-life measure for adults with primary ciliary dyskinesia: QOL-PCD. Eur Respir J 2015; 46: 375-383.

38 Chalmers JD, Aliberti S, Blasi F. Management of bronchiectasis in adults. Eur Respir J 2015; 45: 1446-1462.

39 Aliberti S, Masefield S, Polverino E, et al. Research priorities in bronchiectasis: a consensus statement from the EMBARC clinical research collaboration. Eur Respir J 2016; 48: 632-647.

40 Aliberti S, Lonni S, Dore S, et al. Clinical phenotypes in adult patients with bronchiectasis. Eur Respir J 2016; 47: $1113-1122$.

41 Greulich T, Nell C, Hohmann D, et al. The prevalence of diagnosed $\alpha_{1}$-antitrypsin deficiency and its comorbidities: results from a large population-based database. Eur Respir J 2017; 49: 1600154

42 Ji J, Sundquist J, Sundquist K. Incidence and familial risk of pleural mesothelioma in Sweden: a national cohort study. Eur Respir J 2016; 48: 873-879.

43 Meyer KC, Raghu G, Verleden GM, et al. An international ISHLT/ATS/ERS clinical practice guideline: diagnosis and management of bronchiolitis obliterans syndrome. Eur Respir J 2014; 44: 1479-1503.

44 Ruttens D, Verleden SE, Bijnens EM, et al. An association of particulate air pollution and traffic exposure with mortality after lung transplantation in Europe. Eur Respir J 2017; 49: 1600484.

45 Benmerad M, Slama R, Botturi K, et al. Chronic effects of air pollution on lung function after lung transplantation in the Systems prediction of Chronic Lung Allograft Dysfunction (SysCLAD) study. Eur Respir J 2017; 49: 1600206.

46 Randerath W, Verbraecken J, Andreas S, et al. Definition, discrimination, diagnosis and treatment of central breathing disturbances during sleep. Eur Respir J 2017; 49: 1600959.

47 Cottin V, Bel E, Bottero P, et al. Respiratory manifestations of eosinophilic granulomatosis with polyangiitis (Churg-Strauss). Eur Respir J 2016; 48: 1429-1441.

48 Vorselaars VM, Velthuis S, Snijder RJ, et al. Follow-up of pulmonary right-to-left shunt in hereditary haemorrhagic telangiectasia. Eur Respir J 2016; 47: 1750-1757.

49 Kotecha S, Barbato A, Bush A, et al. Congenital diaphragmatic hernia. Eur Respir J 2012; 39: 820-829.

50 Harari S, Humbert M, Blasi F, et al. Rare pulmonary diseases and orphan drugs: where do we stand and where are we going to? Eur Respir Rev 2015; 24: 375-377.

51 Harari S, Humbert M. Toward better management of rare and orphan pulmonary diseases. Eur Respir J 2016; 47: 1334-1335. 